\title{
Simulation of a Site-Specific Doubly-Fed Induction Generator (DFIG) for Wind Turbine Applications
}

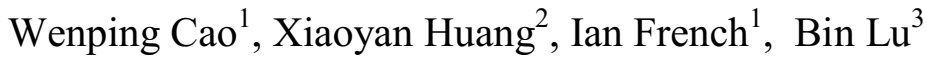 \\ 1: School of Science and Technology \\ University of Teesside \\ United Kingdom \\ w.cao@tees.ac.uk \\ 2: School of Electrical and Electronic Engineering \\ University of Nottingham \\ United Kingdom \\ 3: Eaton Corporation, Milwaukee, United States
}

\begin{abstract}
This paper describes a preliminary study of a $30 \mathrm{~kW}$ doubly-fed induction generator (DFIG) used for wind turbine applications. Wind represents a variable-speed intermittent source of energy in nature and can be controlled to be a nearly constant speed but variable-torque input to the wind turbine using blade pitch angle regulation. Wind profile at the installation site is investigated so as to derive parameterized wind speeds, more importantly, the annual cubic-mean speed. This is taken account into the machine design since the machine efficiency varies with turbine mechanical inputs. By coordinating the loss components, it is possible at the machine design stage to select the maximum efficiency to be near the actual optimized load, in a long run, to maximize the overall energy production of the generator. The DFIG is modeled in Matlab with a vector control. The total energy production is used as a key criterion to refine the machine design.
\end{abstract}

\section{INTRODUCTION}

In recent years there has been a growing interest in exploiting renewable energy sources for the generation of electrical energy and, at this moment of time, it is wind energy that is firmly in the spotlight. For wind turbine applications, the doubly-fed induction generator (DFIG) has proved to be very popular, especially for large wind farms. As a result, numerous studies have been conducted to maximize the wind energy capture [1][2], to optimize the control strategies [3][4], and to investigate the impact of such machines when connected to an electricity network [5][6].

Matching machine characteristics of the wind turbine generators with site-specific wind profiles have been attempted previously [1][2][7][8]. However, these machines are all offthe-shelf products. In essence, site matching is conducted by predicting the maximum electricity generation from some commercially available machines. In terms of machine design, little effort has been made to match machine characteristics with the site wind profile.

This study incorporates site-specific wind profiles into the machine characteristics at the design stage by balancing the loss components and by optimizing the efficiency-torque characteristic. The ultimate purpose is to select the maximum machine efficiency to be near the actual optimized load condition which corresponds to the cubic-mean wind speed of the particular site selected.

The DFIG is modeled in Matlab with a typical vector control for both torque and speed control. The total energy production is used as a key criterion to refine the machine design.

\section{LOSS COMPONENTS AND MACHINE EFFICIENCY}

In the literature, power losses and efficiency of induction machines have been extensively investigated. Like other types of induction machines, DFIGs also have five basic loss components:

- Stator conductor loss $-\mathrm{I}^{2} \mathrm{R}$ losses in the stator winding.

- Rotor conductor loss $-\mathrm{I}^{2} \mathrm{R}$ losses in the rotor winding.

- Core loss- power losses in active iron and other metal parts in the stator and rotor. Stator core loss is a function of actual magnetization voltage.

- Friction and windage losses - power losses due to mechanical friction of bearings and internal cooling fans. These losses are a function of actual shaft speed.

- Stray load loss-all other sources not accounted for by the above four components. It is generally considered as being proportional to the load torque squared [9]-[10].

Among these losses, the determination of the stray load loss has been a challenge for a long time. This is due to its complex mechanism and small magnitude. Therefore, empirical methods of quantifying stray load loss are widely adopted [10].

The accurate determination of machine efficiency is a more difficult task than it would appear. Firstly, the rated efficiency figure alone is not sufficient for predicting the machine performance under variable load conditions. This is particularly the case in wind turbine applications where machine input power constantly varies with wind speeds.

To make things worse, it is often the case that the maximum efficiency of induction machines does not occur at the rated load, nor the most frequently operating load. Previous research [11] has suggested that the machine efficiency would reach its peak value where the load-dependent losses equate the loadindependent losses. The former consists of stator conductor loss, rotor conductor loss and stray load loss, and the latter, 
core loss, friction and windage losses. By coordinating these loss components, it is possible to shift the maximum efficiency close to any desired operational condition.

Fig. 1 shows such an example where the efficiency curve of a $75 \mathrm{~kW}$ induction machine has been modified in the process of machine rewinding, primarily by reducing the length of stator windings. In effect, the decrease in the stator conductor loss causes the maximum efficiency to move to a higher load point. In simpler terms, loss balancing can be generally considered as an issue of copper versus iron in the machine design.

\section{WIND PROFILE AND ANALYSIS}

The long term wind profile provides fundamental information for evaluation of available wind energy. In this paper, annual wind speed data for a site in the Northeast England have been obtained through the UK Meteorological Office. As shown in Fig. 2 for a period of February 2006 to January 2007, wind speeds for this site were varying significantly.

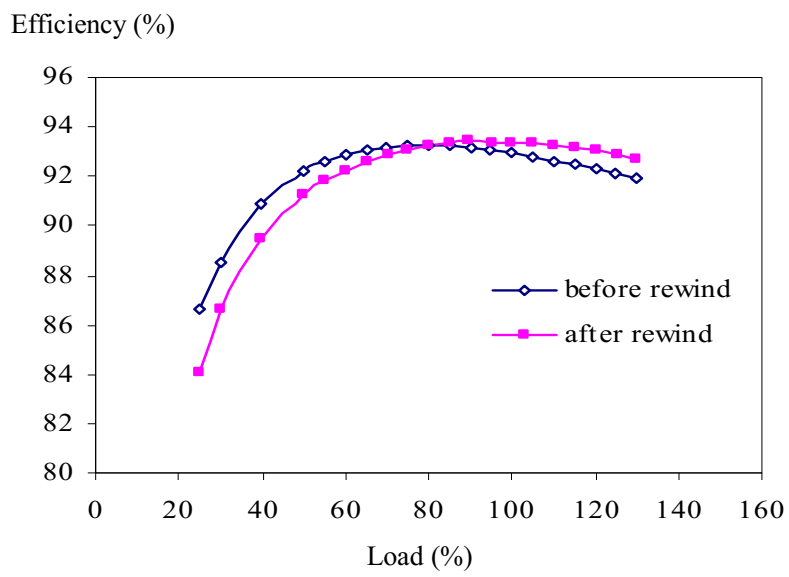

Fig. 1. Change in efficiency due to rewinding

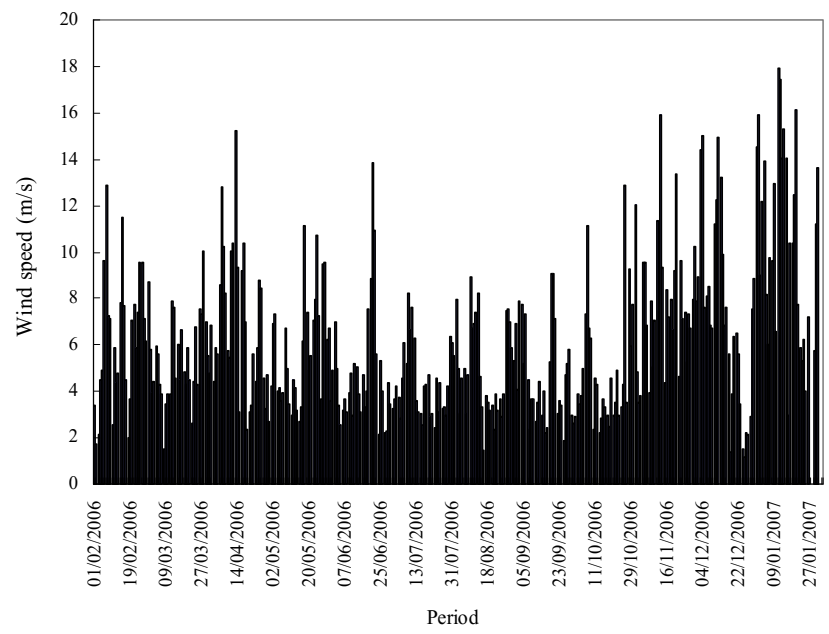

Fig. 2. Annual wind speed variations for the site
Wind speed data are commonly analyzed using statistical methods, such as probability density function. Wind speeds can be characterized as arithmetic mean, root mean and cubic mean values. It is reported that the cubic mean wind speed is more realistic compared to the arithmetic and root mean values [1].

The cubic mean wind speed is calculated using the equation in [12].

$$
V_{m 1}=\left(\frac{\sum_{i=1}^{N} V_{i}^{3}}{N}\right)^{\frac{1}{3}}
$$

where $V_{\mathrm{m} 1}$ is the mean wind speed, $N$ is the number of wind speed observations, and $V_{\mathrm{i}}$ is the observed wind speed sample.

After the mean wind speed is derived, it needs to be corrected to the hub height at the given site, using the equation below,

$$
V_{m}=V_{m 1}\left(\frac{H}{H_{r}}\right)^{x}
$$

where $V_{\mathrm{m}}$ is the mean wind speed at the projected height, $H$ is the projected hub height, $H_{\mathrm{r}}$ is the reference height where the wind data are obtained (usually $10 \mathrm{~m}$ ), and $x$ is surface roughness coefficient. For open land, $x$ is usually taken as $1 / 7$ [7].

This mean wind speed is then translated into an suitable input power to the generator under rated condition, through the wind turbine, gearbox and drive train. Loss balance is conducted to shift the maximum efficiency close to this condition. However, the effectiveness of this technique needs to be verified by actual annual energy yield.

Energy production calculations are based on probability density functions. Commonly, Weibull and Rayleigh probability density functions are two types in use [13] but Weibull is thought to provide a better approximation for wind energy calculations [7].

The input power to a wind turbine at a particular site depends on the wind speeds of the site with respect to its hub height. More precisely, the power is a cubic function of wind speeds. This is the reason why the cubic-mean wind speed is effective to represent the wind profile. However, a wind turbine can only utilize a portion of this incoming power, subject to its characteristics, particularly the cut-in speed $\left(V_{\text {in }}\right)$, the cut-out speed $\left(V_{\text {out }}\right)$, and the rated speed $\left(V_{\text {rated }}\right)$ of the wind turbine. Fig. 3 illustrates the desired generator output characteristics in relation to the wind speeds.

Ideally, the output power should be smooth and constant. This is realized only for wind speeds above the rated. The rotor speed is controlled with adjustable pitch actuators to shed the aerodynamic power for the high wind speed region.

The overall power yield from the DFIG can be predicted by multiplying the power produced at each discrete wind speed and the probability of that wind speed occurring for this particular site. 


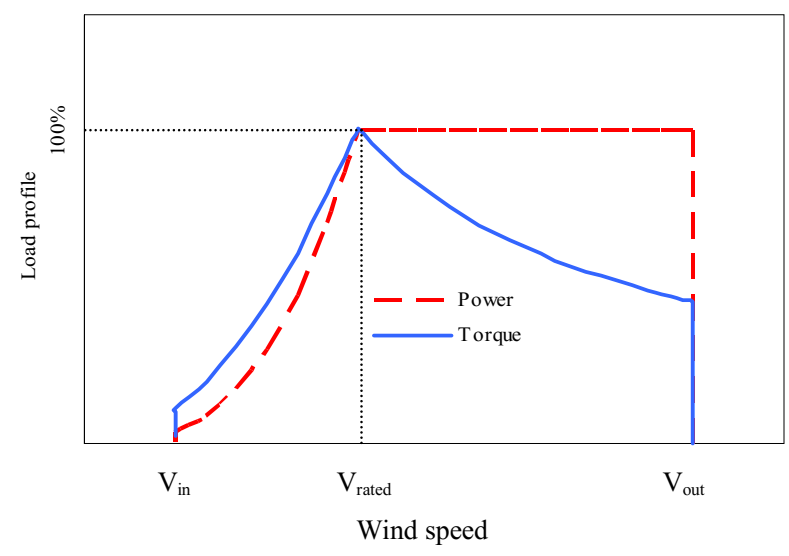

Fig. 3. The DFIG load characteristics

\section{MODELING OF THE DFIG}

The machine designed in this paper is a 4-pole $30 \mathrm{~kW}$ DFIG and its specifications are listed in Table I. The nominal speed of the DFIG is $1500 \mathrm{rpm}$ with a torque of $191 \mathrm{Nm}$. The operational speed ranges from $500 \mathrm{rpm}$ up to $3500 \mathrm{rpm}$. The target efficiency is at least $90 \%$ at rated load which means that an overall system efficiency of $80 \%$ may be achieved, allowing for some losses in the turbine, gearbox, drive train and power electronics.

Stator and rotor conductor losses, and core loss are calculated taking account of stator flux saturation. Friction and windage losses are estimated using the data from the bearing and fan manufacturers. Stray load loss is assumed to be $1.8 \%$ of output power as suggested in the IEEE standard 112 method E [9].

The DFIG is coupled to the turbine through a gearbox. The stator winding is directly connected to power grid through a step-up transformer and the rotor winding is connected to back-to-back power converters through slip rings.

TABLE I

MACHINE SPECIFICATIONS

\begin{tabular}{|l|r|}
\hline \multicolumn{1}{|c|}{ Parameter } & Rated value \\
\hline Voltage $(\mathrm{V})$ & $415 \mathrm{~V}$ \\
\hline Current $(\mathrm{A})$ & $49 \mathrm{~A}$ \\
\hline Frequency $(\mathrm{Hz})$ & $50 \mathrm{~Hz}$ \\
\hline Speed $(\mathrm{rpm})$ & $1500 \mathrm{rpm}$ \\
\hline Torque $(\mathrm{Nm})$ & $191 \mathrm{Nm}$ \\
\hline Stator resistance & $0.6 \Omega$ \\
\hline Rotor resistance & $0.258 \Omega$ \\
\hline Stator inductance & $0.0844 \mathrm{H}$ \\
\hline Rotor inductance & $0.0821 \mathrm{H}$ \\
\hline Leakage inductance & $0.0803 \mathrm{H}$ \\
\hline
\end{tabular}

The DFIG is controlled by power converters with reduced power rating through the rotor-side inverter. As shown in Fig. 4 , this is a stator flux oriented $\alpha \beta$-frame DFIG model a vector control. The voltage applied on stator winding is therefore changed to $\alpha \beta$-frame. The input is $I_{\mathrm{rd}}$ and $I_{\mathrm{rq}}$ and the output of the model is the 3-phase current in the stator and rotor.

In the simulation, $I_{\mathrm{rd}}$ is set to zero initially and $I_{\mathrm{rq}}$ is modified to get proper torque. By changing the $I_{\mathrm{rq}}$ reference, the desired torque can be achieved which is proportional to $I_{\mathrm{rq}}$. After this, the current in stator and rotor can be found as well as the stator and rotor conductor losses.

\section{NUMERICAL RESUlTS AND DISCUSSION}

Having acquired the loss information by Matlab and empirical data, the machine efficiency is then computed for a particular input condition. By repeating this process across the whole load range, a complete efficiency curve can be obtained. Power loss coordination is then conducted in Matlab and this provides guidance on which loss component to modify in order to match the maximum efficiency with the cubic-mean wind speed. This "best possible" power yield is also used to validate the machine design.

The efficiency curve at various load conditions is shown in Fig. 5. It can be seen that the maximum efficiency is achieved at approximately $90 \%$ load condition where the fixed losses (core and WF losses) are equal to the variable losses (stator, rotor conductor losses, and stray load loss).

As the winding of the DFIG has great impact on produced torque. The efficiency data varied with the stator inductance are also investigated based on the assumption of the equal utilization of copper. This is conducted by modifying the stator and rotor inductance which may be subject to the winding arrangement. In this process, the ratio of stator and rotor inductance is kept constant. In adjusting the value of $I_{\mathrm{rq}}$ to attain the rated torque, the current in the stator and rotor $\left(I_{\mathrm{sabc}}\right.$

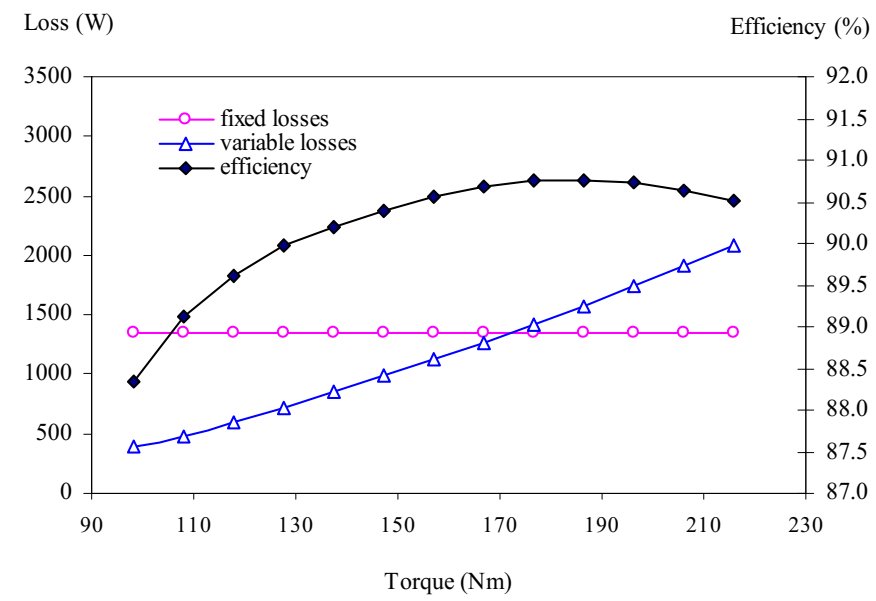

Fig. 5. Efficiency varied with load torque 


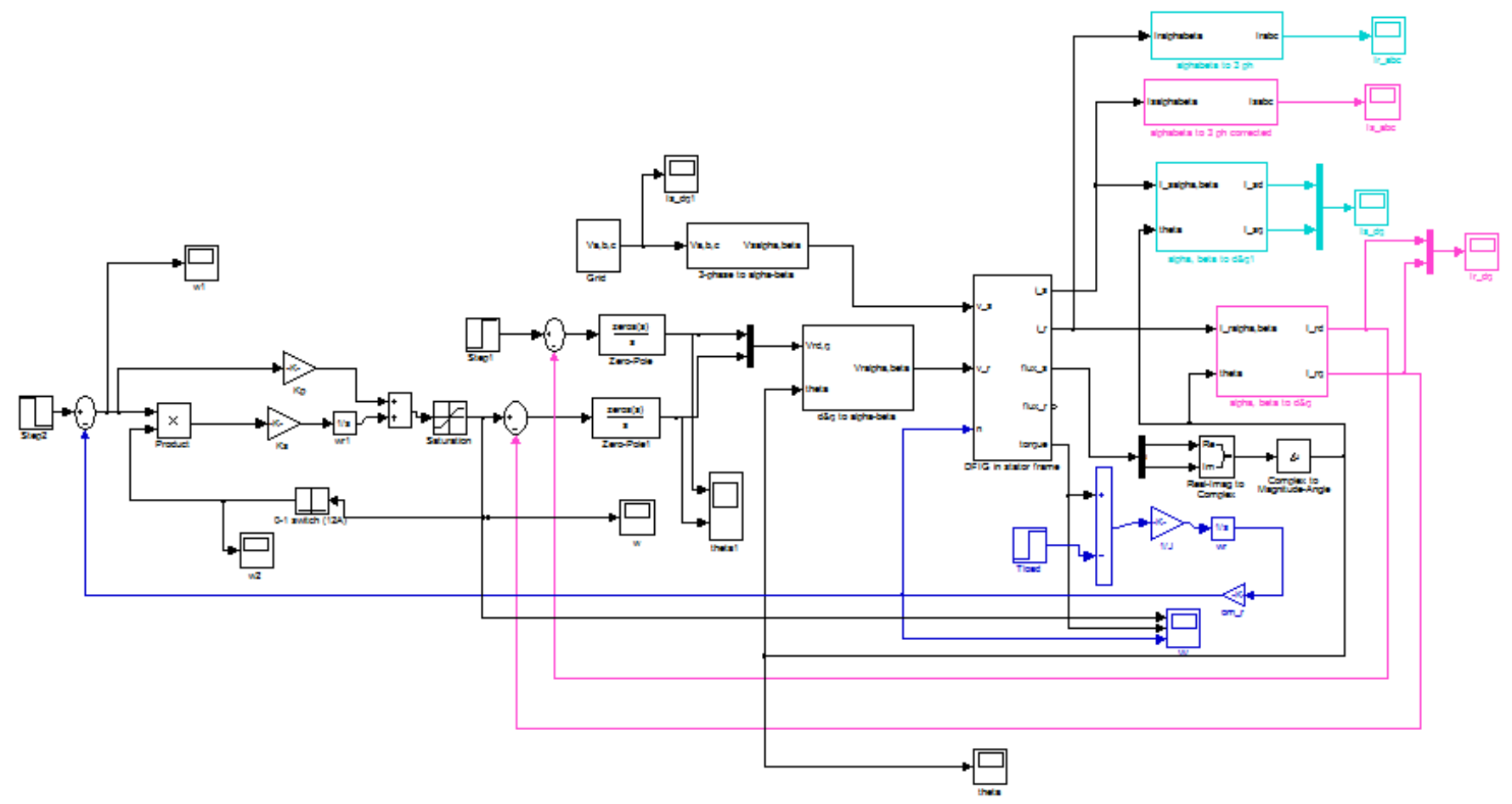

Fig. 4. Vector control of the DFIG

and $I_{\text {rabc }}$ ) can be derived as well as the corresponding conductor losses.

From Fig. 6, it can be seen that the efficiency tends to reduce as the stator inductance increases in the range of $0.08-0.14$ Henrys. This observation is used for refining the machine so as not to increase the stator inductance when altering the stator winding design in loss balancing.

\section{CONCLUSIONS}

The paper has presented a preliminary study of a sitespecific DFIG for variable-speed wind turbine applications.

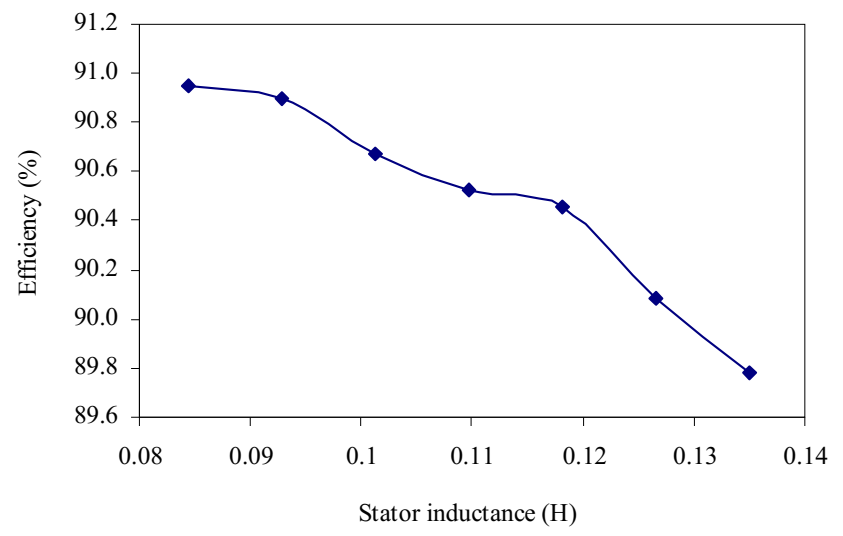

Fig. 6. Efficiency varied with stator inductance
The wind speed characteristics are attained in this study to derive a parameterized wind model for calculation of input power to the wind turbine generator. Modeling of the machine under a particular input condition provides information of stator and rotor conductor losses and core loss. Friction and windage losses are based on the manufacturers' data while stray load loss is estimated using the empirical factor suggested by the IEEE 112-E. A full efficiency curve is then used to derive a total energy production which serves as a refinement criterion for the machine design. Loss coordination is conducted in Matlab so as to shift the maximum efficiency to the desired operational condition corresponding to the cubicmean wind speed.

In the further work, the site-matching machine design can be considered in more detailed variations, such as various stator and rotor winding types and slot representations. The refined machine can be validated by calculating the maximum energy production.

\section{ACKNOWLEDGMENT}

The author would like to acknowledge the helpful discussions with Prof K. J. Bradley on the preparation of this paper.

\section{REFERENCES}

[1] S.H. Jangamshetti, V.G. Rau, "Site matching of wind turbine generators: a case study", IEEE Transactions on Energy Conversion, Volume 14, Issue 4, Dec. 1999, pp: 1537-1543 
Proceedings of the 2008 International Conference on Electrical Machines

[2] S.H. Jangamshetti, V.G. Rau, "Normalized power curves as a tool for identification of optimum wind turbine generator parameters", IEEE Transactions on Energy Conversion, Volume 16, Issue 3, Sept. 2001, pp: 283-288

[3] E.S. Abdin, W. Xu, "Control design and dynamic performance analysis of a wind turbine-induction generator unit", IEEE Transactions on Energy Conversion, Volume 15, Issue 1, March 2000, pp: 91-96

[4] J.B. Ekanayake, L. Holdsworth, XueGuang Wu, N. Jenkins, "Dynamic modeling of doubly fed induction generator wind turbines", IEEE Transactions on Power Systems, Volume 18, Issue 2, May 2003, pp: 803809

[5] Z. Saad-Saoud, N. Jenkins, "Models for predicting flicker induced by large wind turbines", IEEE Transactions on Energy Conversion, Volume 14, Issue 3, Sept. 1999, pp: 743-748

[6] R. Teodorescu, F, Blaabjerg, "Flexible control of small wind turbines with grid failure detection operating in stand-alone and grid-connected mode", IEEE Transactions on Power Electronics, Volume 19, Issue 5, Sept. 2004, pp: 1323-1332

[7] Z.M. Salameh, I. Safari, "Optimum windmill-site matching", IEEE Transactions on Energy Conversion, Volume 7, Issue 4, Dec. 1992, pp: 669-676
[8] R. Billinton, H. Chen, "Determination of the optimum site-matching wind turbine using risk-based capacity benefit factors", IEE Proceedings on Generation, Transmission and Distribution, Volume 146, Issue 1, Jan. 1999, pp: $96-100$

[9] IEEE Std 112-2004 (IEEE 112-1991, 1996), IEEE Standard Test Procedure for Polyphase Induction Motors and Generators (ANSI)

[10] IEC 60034-2-1: 2007 (BS EN 60034-2-1) Rotating Electrical MachinesPart 2-1: Standard methods for determining losses and efficiency from tests (excluding machines for traction vehicles)

[11] Wenping Cao, K.J. Bradley, "Assessing the impacts of rewind and repeated rewinds on induction motors: is an opportunity for re-designing the machine being wasted?", IEEE Transactions on Industry Applications, Volume 42, Issue 4, July-Aug. 2006, pp: 958-964

[12] E.W. Golding, "The generation of electricity by wind power", $E \& F$ Spon, London, England, 1975

[13] S. Rahman and B. Matheny, "Wind system assessment for electric utilities", American Solar Energy Society Annual Meeting and the Wind Energy Workshop IV, Minnesota, June 1983 